\title{
Urogenital schistosomiasis burden in school-aged children in Tiko, Cameroon: a cross-sectional study on prevalence, intensity, knowledge and risk factors
}

\author{
Irene Ule Ngole Sumbele ${ }^{1,3}$, Doris Bennen Tabi ${ }^{2}$, Rene Ning Teh ${ }^{1 *}(0)$ and Anne Longdoh Njunda ${ }^{2}$
}

\begin{abstract}
Background: This study aimed at determining urogenital schistosomiasis (UGS) prevalence, intensity, knowledge and risk factors in school-aged children (SAC) in the new endemic focus of Tiko, Cameroon.

Methods: A cross-sectional study including 389 SAC of both sexes aged 5-15 years was carried out between April and June 2018. A structured questionnaire was used to collect demographic data, clinical and predisposing factors. Urine sample collected was used to detect Schistosoma haematobium eggs by filtration technique and microhaematuria by Heme dipstick COMBI 11. Logistic regression model was used to determine risk factors of UGS.

Results: The overall prevalence of UGS was $37.0 \%(\mathrm{Cl} 32.4-41.9)$ and $32.6 \%(\mathrm{Cl} 28.2-37.5)$ were positive by egg excretion while $24.4 \%$ (Cl 20.4-28.9) by haematuria. S. haematobium egg excretion and haematuria were significantly higher in males $(P=0.016 ; P=0.049)$ and children $12-15$ years old $(P=0.009 ; P=0.002)$, respectively. The mean number of eggs per $10 \mathrm{~mL}$ of urine was 77.6 (10.2) and ranged from 2 to 400 . The proportion of light intensity of infection was higher (67.7\%, Cl 59.2-75.2) with no significant differences by sex, age and residence. However, the older children were more heavily infected when compared to the younger children, who had more of light infection. Overall, the mean knowledge score 1.42 (Cl 1.32-1.51) on a scale of 6 , was poor and the proportion of good knowledge of the disease $(23.14 \%, \mathrm{Cl} 19.2-27.6)$ was low. Stream water contact $(A O R=4.94 ; P=0.001)$ was the only significant risk factor identified.

Conclusion: Urogenital schistosomiasis is of public health concern among SAC in Tiko, Cameroon. Most participants have poor knowledge about the disease, hence education on vector-borne diseases and the avoidance of stream water contact should be implemented.
\end{abstract}

Keywords: Urogenital schistosomiasis, Prevalence, Risk factors, Knowledge, School-aged children

\section{Background}

Neglected tropical diseases are often associated with serious disabilities and very high mortality rates, with more than a billion people affected and projections of millions

*Correspondence: teh.rene@ubuea.cm

${ }^{1}$ Department of Zoology and Animal Physiology, University of Buea, Buea, Cameroon

Full list of author information is available at the end of the article of disability-adjusted life years [1]. Schistosomiasis which is a neglected tropical disease, is second to malaria alone amid the vector-borne diseases in terms of public health [2]. It is second to none in terms of prevalence amongst water-borne diseases [3]. A great majority $(85 \%)$ of cases occur in Africa [4]. Despite the gains in the health care delivery of the past decades, schistosomiasis has prevailed as a health challenge in the tropics and sub-tropics. original author(s) and the source, provide a link to the Creative Commons licence, and indicate if changes were made. The images or other third party material in this article are included in the article's Creative Commons licence, unless indicated otherwise in a credit line to the material. If material is not included in the article's Creative Commons licence and your intended use is not permitted by statutory regulation or exceeds the permitted use, you will need to obtain permission directly from the copyright holder. To view a copy of this licence, visit http://creativecommons.org/licenses/by/4.0/. 
Schistosomiasis is a disease of the poor who live in conditions that favour transmission; an insidious disease, poorly recognized at early ages and disabling to men and women during their most productive years [5]. Schistosomiasis is caused by several species of the genus Schistosoma. It can be grouped into two categories based on the organ affected-urogenital schistosomiasis and intestinal schistosomiasis. Urogenital schistosomiasis is caused by Schistosoma haematobium and intestinal schistosomiasis by any of the following organisms namely, S. guineensis, S. intercalatum, S. mansoni, S. japonicum, and S. mekongi.

Urogenital schistosomiasis (UGS) caused by S. haematobium is acquired from infested freshwater snails of the Bulinus species. Its transmission takes place only where snail vectors are present and where there is contact between the population and infected freshwater sources containing parasites egg which hatch in the water [6]. People become infected when larval forms of the parasite (cercaria) released by freshwater snails penetrate the skin during contact with infested water. In the body, the larvae develop into adult schistosomes and the parasite is found in the venous plexus draining the urinary bladder of humans [7]. Various socio-epidemiological factors are responsible for transmission of the disease amongst which are migration, distance from transmission site and emergence of new foci, which is the main factor in this present case [8].

The characteristic clinical presentation of infection with S. haematobium is terminal haematuria, usually associated with increased frequency of micturition and dysuria. The infection is also associated with anaemia [9], nutritional deficiencies and growth retardation [10], adverse effects on cognitive development, decreasing physical activity and school performance as well as work capacity and productivity [11]. Diagnosis is made by finding the characteristic ova in the urine using the filtration techniques.

Alongside malaria, schistosomiasis is also a documented public health problem in Cameroon and contributes to a third of the morbidity among school-age children (SAC) [12, 13]. The mainstay of schistosomiasis control in endemic foci in Cameroon is preventive chemotherapy-the periodic administration of praziquantel to at-risk groups (e.g., school-age children (4-14 years) in schools or through community directed programmes [14]. While this strategy does not prevent infection or reinfection, it reduces morbidity and might also influence transmission [15]. Despite all the efforts put in place by the Ministry of Public Health in Cameroon to curb UGS and to reduce its outbreak, it remains an undiminishing threat with new foci such as Tiko, on the rise, which has not benefitted from this control. Tiko is a semi-urban area with many streams that have been used by the inhabitants for laundry, swimming and fishing, exposing the population to water and vector-borne disease.

Recent report highlights the emergence of urogenital schistosomiasis among SAC and reproductive aged individuals in Likomba, a community in Tiko Health District $[16,17]$. It is therefore vital to monitor the variation of intensity of infection and associated morbidity in Likomba and another closer neighbourhood like Upper Costen in the same Health District suspected for UGS, due to the migration of individuals from the conflict-hit areas of Muyuka and Ikata-Likoko, endemic with UGS $[18,19]$. The consequences of the ongoing civil strife in the North West and South West Regions of Cameroon have been enormous $[19,20]$, with over half a million people displaced the majority of whom are women and children [21]. The main objective of this study was to generate baseline data on the prevalence of UGS in SAC in Tiko; raise awareness through evaluation of knowledge of the disease as well as identify risk factors to enable strategic planning of control programmes in this endemic focus.

\section{Materials and methods Study area and participants}

The study was carried out in Likomba and Upper Costen in the Tiko Health District in the South West Region of Cameroon. The map showing the study sites and existing water bodies is represented in Fig. 1. A detailed description of the study area is given in Anguh et al. [16]. Tiko municipality has a coastal equatorial climate. There is poor urban planning with some houses having neither toilets nor water, while some share toilets in a group. Defecation is done in empty plots of land common in the area. Due to influx of internally displaced persons from conflict-hit areas and conditions of poor personal hygiene and environmental sanitation, diseases like schistosomiasis are bound to be on the rise. The town partly hosts the CDC (Cameroon Development Co-operation) industrial farms, which produces rubber, banana and palm oil.

The study population included SAC of both sexes aged 5-15 years whose parent or guardian consented through signing an assent form to their participation in the study. Participants were recruited if they met the eligibility criteria of being $\geq 5$ years and $<16$ years, lived in the area for at least a year before the commencement of the study, demonstrated the willingness to participate in the study and could understand English/French or could respond to questions asked in pidgin.

\section{Study design and sampling}

This community-based cross-sectional study was carried out in Tiko in the South West Region of Cameroon within the period of April to May 2018. SAC from Upper 


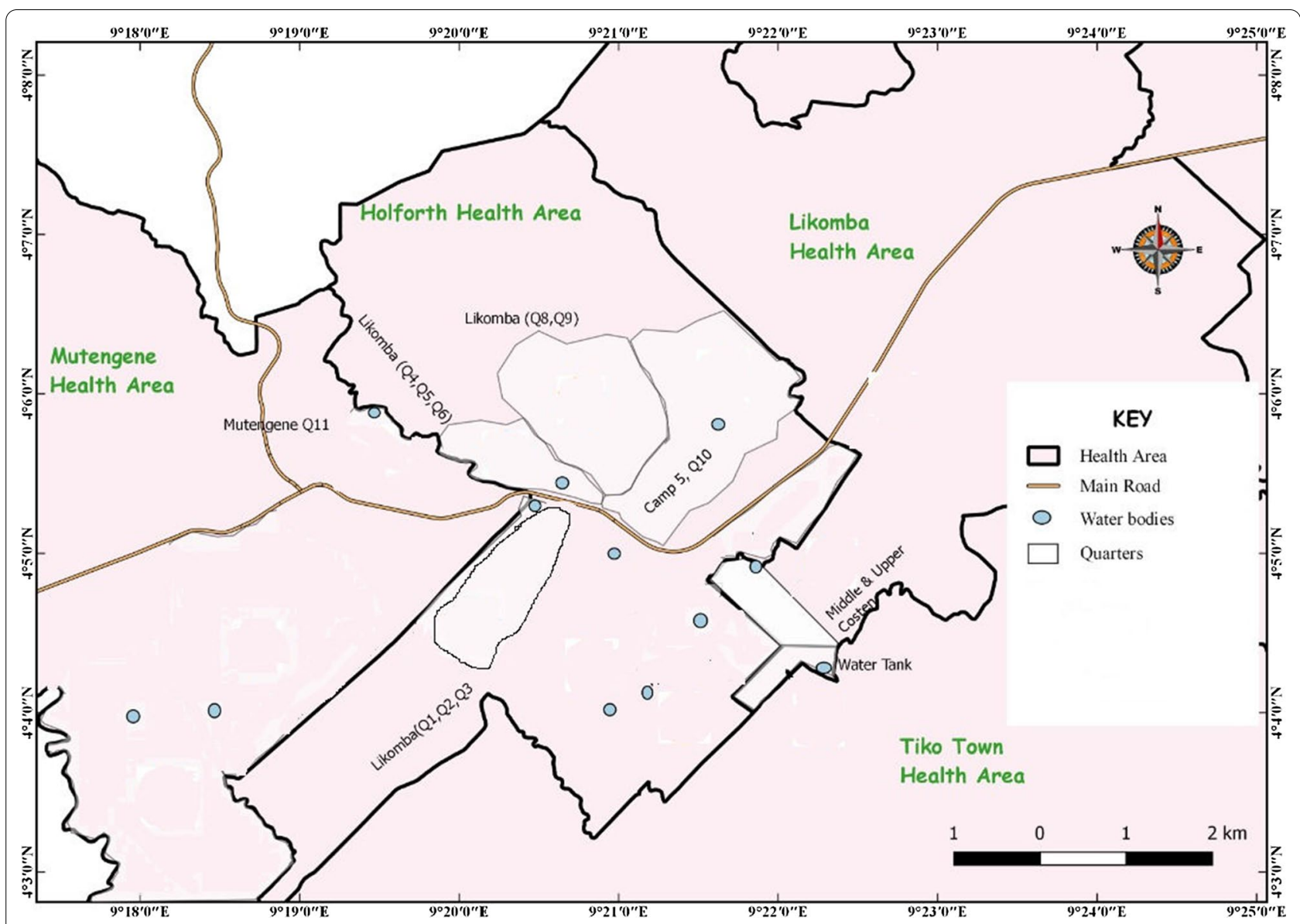

Fig. 1 Map showing the study sites (Likomba and Upper Costen) and water bodies

Costen and Likomba were recruited by a convenience sampling method as they presented themselves to the research team following education through community relay agents. Children whose parent/guardian signed the informed consent/assent form following education were enrolled. Data on socio-demographics, clinical, perceptions and knowledge on UGS, were collected using a simple structured questionnaire. Confidentiality was taken into consideration as participants responded to the questions in the questionnaire. Subsequently, each participant was given a sterile, wide mouthed, screw-capped plastic container carrying their identification numbers and instructions on how to collect the urine samples.

\section{Sample size determination}

The sample size of the study population was determined using the formula $n=Z^{2} p q / d^{2}$ [22], where $\mathrm{n}$ was the sample size required; $Z$ was 1.96 , which is the standard normal deviate (for a 95\% confidence interval, CI); $p$ was $38 \%$, the proportion of UGS prevalence reported in the area [14]; $q$ was $1-p$, the proportion of UGS negative; and $d$ was 0.05 , the acceptable error willing to be committed. The optimum sample size was estimated to be 362 . A total of 389 participants were enrolled into the study in anticipation of incomplete data entry, loss of data, voluntary withdrawal and for superior precision.

\section{Data collection}

A simple semi-structured questionnaire was pretested in urogenital schistosomiasis endemic focus of Muyuka. The respondents selected for pre-testing of the questionnaire consisted of 50 parents/caregivers above 18 years of age, of both sexes and different levels of education. The questionnaire was modified accordingly before being administered. The information collected included demographic, socio-economic, environmental background, personal hygiene, clinical signs and symptoms of UGS; household cleanliness including availability of functioning toilets, use of pipe-borne water, wearing shoes when outside the house and washing of hands. The children's parents or adult guardians were the respondents and those who could not read or write were aided via a faceto-face interview. 


\section{Urine sample collection and processing}

About $20 \mathrm{ml}$ of midstream urine sample was collected into a clean, dry, open mouth, capped and labelled container after a brisk exercise between $10 \mathrm{am}$ and $2 \mathrm{pm}$. The urine sample was immediately checked for microhaematuria using the Heme dipstick COMBI 11 by dipping it in the urine and reading after $120 \mathrm{~s}$ for colour changes following the manufacturers instruction. The samples were preserved in a cooler (temperature: $2-8{ }^{\circ} \mathrm{C}$ ) and transported to the Malaria Research Laboratory of the University of Buea for processing and examination. All samples were examined no later than $12 \mathrm{~h}$ after collection. Filtration technique was used as a quantitative test following standard procedure [23]. Briefly, using blunt-ended forceps, a polycarbonate filter (STERLITECH Corporation USA) was carefully placed in the filter support of the filter holder. The filter holder was reassembled and attached to the end of a $10-\mathrm{mL}$ syringe. The syringe was filled to the $10-\mathrm{mL}$ mark with well mixed urine and the urine sample passed through the filter. With the aid of blunt forceps, the filter was removed after unscrewing the filter holder and transferred face upwards, that is eggs on the surface on a microscope slide. A drop of iodine was added to the slide and covered with cover glass. Using the $\times 10$ objective the entire filter was examined systematically for $S$. haematobium egg and the total number of eggs seen was counted and recorded per $10 \mathrm{~mL}$ of urine. The intensity of infection was reported as light infection (1-49 eggs/10 mL of urine) while 50 eggs and above/10 mL of urine was classified as heavy infection [24].

\section{Data analysis}

Data were double entered by two different researchers into a spreadsheet of SPSS version 25.0. Then a third researcher crosschecked the two data sets for accuracy and created a single data set for data analysis. Sociodemographic characteristics were treated as categorical variables and presented as frequencies and percentages. The prevalence of UGS was presented as proportions. Intensity of UGS was expressed as proportion of light and heavy infection and Chi-square $\left(\chi^{2}\right)$ was used to examine the association between infection intensity and demographic factors (sex and age). A multivariate logistic regression analysis was used to identify the risk factors that were significantly associated with UGS. Odds ratio (OR), adjusted odds ratio (AOR) and a 95\% confidence interval $(\mathrm{CI})$ were computed for each variable. The level of statistical significance was set as $P<0.05$.

Mean knowledge scores and proportions were used to determine the level of good knowledge of participants on UGS. For knowledge scoring and analysis, a total of six item or questions were included in the knowledge section which included elementary knowledge on the cause, mode of transmission and prevention of schistosomiasis. For these six knowledge questions, the maximum attainable score was ' 6 ' and the minimum score was ' 0 '. The level of knowledge was classified according to each respondent's score. Good knowledge corresponds to a score greater than 3 (i.e. participants with more than 3 correct responses out of the 6 knowledge questions) while poor knowledge corresponded to a score less than 3 (i.e. participants with less than 3 correct responses out of the 6 knowledge questions).

\section{Definition of end points}

UGS: presence of schistosomiasis when diagnosed positive by microscopic examination and/or urine reagent strips.

Haematuria: presence of schistosomiasis when diagnosed positive by urine reagent strips.

\section{Results}

Socio-demographic characteristics of participants

A total of 389 SAC (53.4\% males and $46.6 \%$ females) aged between 5 and 15 years, with a mean age of $9.4 \pm 3.1$ years were enrolled in this study. Of these, $43.4 \%$ resided in Upper Costen and 56.6\% resided in Likomba. Majority (75.6\%) of the participants were in primary school and only one-third $(32.7 \%)$ of the households owned a latrine (Table 1).

\section{Prevalence and intensity}

Out of the 389 SAC examined, 32.6\% (CI 28.2-37.5) were S. haematobium egg positive with similar prevalence in Upper Costen (31.4\%, CI 24.9-38.7) and Likomba (33.6\%, CI 27.7-40.1). However, the prevalence was significantly higher in males $(38.0 \%$, CI $31.7-44.7)$ and those

Table 1 Socio-demographic characteristics of participants

\begin{tabular}{llll}
\hline Variable & Category & Frequency & Percent (\%) \\
\hline Gender & Male & 208 & 53.47 \\
& Female & 181 & 46.53 \\
& $5-8$ & 156 & 40.10 \\
Age (years) & $9-11$ & 121 & 31.10 \\
& $12-15$ & 112 & 28.79 \\
Mean age & $9.4 \pm 3.4$ & & \\
(years) \pm SD & & & \\
Educational level & Primary education & 294 & 75.58 \\
& Secondary education & 95 & 24.42 \\
Household owns a & Yes & 127 & 32.65 \\
latrine & No & 262 & 67.35 \\
Area of residence & Upper Costen & 169 & 43.4 \\
& Likomba & 220 & 56.6 \\
\hline
\end{tabular}


$12-15$ years (42.0\%, CI 33.2-51.2) old than their counterparts as shown in Table 2.

The mean (SD) number of eggs per $10 \mathrm{~mL}$ of urine was 77.6 (10.2) and ranged from 2 to 400. The proportion of SAC with light intensity of infection (1-49 eggs/10 mL of urine) was higher (67.7\%, CI 59.2-75.2) than that with heavy intensity infection ( $\geq 50$ eggs $/ 10 \mathrm{~mL}$ of urine). No significant variations in eggs excretion intensity were observed between sexes $(P=0.329)$, age groups $(P=0.947)$ and residence $(P=0.202)$ (Table 2). However, the older children were more heavily infected when compared to the younger children, who had more of light infection $(r=0.2, P=0.001)$ as shown in Fig. 2.

Haematuria was common in $24.4 \%$ (CI 20.4-28.9) of the study population with statistically significant variation by sex $(P=0.049)$ and age $(P=0.002)$. The prevalence was significantly higher in males than females $(28.5 \%, \mathrm{CI}$ $22.7-34.8$ vs $19.9 \%$, CI $14.7-26.3$ ) and increased with age from $17.3 \%$ (CI 12.2-24.0) in those 5-8 years old to $35.7 \%$ (CI 27.5-44.9) in those $12-15$ years old as revealed in Table 2.

Participant knowledge of urogenital schistosomiasis (UGS) The proportion of participants with good knowledge on UGS was $23.1 \%$ (CI 19.2-27.6). Only $19.3 \%$ (CI $15.7-$ 23.5) of the participants had ever heard about UGS with the school being the main source of information $12.1 \%$ (CI 9.2-15.7). Barely 19.3\% (CI 15.7-23.5) of the participants knew UGS was transmitted via water. Concerning the signs and symptoms, $11.1 \%$ (CI 8.3-14.6) of them identified haematuria as the main symptom of UGS and 54.3\% (CI 49.3-59.1) were aware the disease could be treated. Regarding methods of prevention, majority (82.8\%, CI 84.3-90.8) had no knowledge on how the disease could be prevented while $7.5 \%$ (CI 5.2-10.5) said it could be prevented by not swimming in water bodies as shown in Table 3.

The combined knowledge score was classified according to each respondent's score. The mean knowledge score of the participants was 1.42 (CI 1.32-1.51) on a scale of 6 . While the proportion of participants with good knowledge on UGS was comparable between those from Upper Costen and Likomba, the proportion significantly increased with age $(\chi 2=15.805 P<0.001)$ with SAC $12-15$ years old (34.8\%, CI 26.6-44.0) being more knowledgeable than their counterparts as shown in Fig. 3. In addition, significantly higher $(\mathrm{X} 2=6.874 P=0.009)$ proportion of males (28.4\%, CI 22.7-34.8) were more knowledgeable of the disease than females.

\section{Risk factors associated with urogenital schistosomiasis in SAC}

Overall, the prevalence of UGS was $37.0 \%$ (144/389) (CI 32.4-41.9). The bivariate and the multivariate logistic regression model with UGS as the dependent variable and age, gender, educational level of parents, knowledge on UGS, source of water for domestic use and water contact, as independent variables is presented in

Table 2 Prevalence and intensity of S. haematobium egg and haematuria by sex, age and residence

\begin{tabular}{|c|c|c|c|c|c|}
\hline \multirow[t]{2}{*}{ Parameter and category } & \multirow[t]{2}{*}{$N$} & \multirow{2}{*}{$\begin{array}{l}\text { S. haematobium egg } \\
\text { prevalence } \%(n)\end{array}$} & \multicolumn{2}{|c|}{ S. haematobium egg intensity } & \multirow{2}{*}{$\begin{array}{l}\text { Haematuria } \\
\text { prevalence }\end{array}$} \\
\hline & & & Light & Heavy & \\
\hline Overall & 389 & $32.6 \%(127)$ & $67.7(86)$ & $32.3(41)$ & $24.4(95)$ \\
\hline \multicolumn{6}{|l|}{ Sex } \\
\hline Male & 208 & $38.0(79)$ & $64.6(51)$ & $35.4(28)$ & $28.4(59)$ \\
\hline Female & 181 & $26.5(48)$ & $72.9(35)$ & $27.1(13)$ & $19.9(36)$ \\
\hline$x^{2}$ & & 5.782 & 0.954 & & 3.87 \\
\hline$P$ value & & 0.016 & 0.329 & & 0.049 \\
\hline \multicolumn{6}{|l|}{ Age (years) } \\
\hline $5-8$ & 156 & $24.4(38)$ & $68.4(26)$ & $31.6(12)$ & $17.3(27)$ \\
\hline $9-11$ & 121 & $34.7(42)$ & $69.0(29)$ & $31.0(13)$ & $23.1(28)$ \\
\hline $12-15$ & 112 & $42.0(47)$ & $66.0(31)$ & $34.0(16)$ & $35.7(40)$ \\
\hline$x^{2}$ & & 9.529 & 0.109 & & 12.123 \\
\hline$P$ value & & 0.009 & 0.947 & & 0.002 \\
\hline \multicolumn{6}{|l|}{ Area of residence } \\
\hline Upper Costen & 169 & $31.4(53)$ & $67.9(36)$ & $32.1(17)$ & $22.5(38)$ \\
\hline Likomba & 220 & $33.6(74)$ & $56.8(42)$ & $43.2(32)$ & $25.9(57)$ \\
\hline$x^{2}$ & & 0.225 & 1.625 & & 0.607 \\
\hline$P$ value & & 0.358 & 0.202 & & 0.436 \\
\hline
\end{tabular}

Light intensity of infection, $1-49$ eggs $/ 10 \mathrm{~mL}$ of urine; heavy intensity of infection, $\geq 50$ eggs/10 $\mathrm{mL}$ of urine. $P$ values in bold are statistically significant 


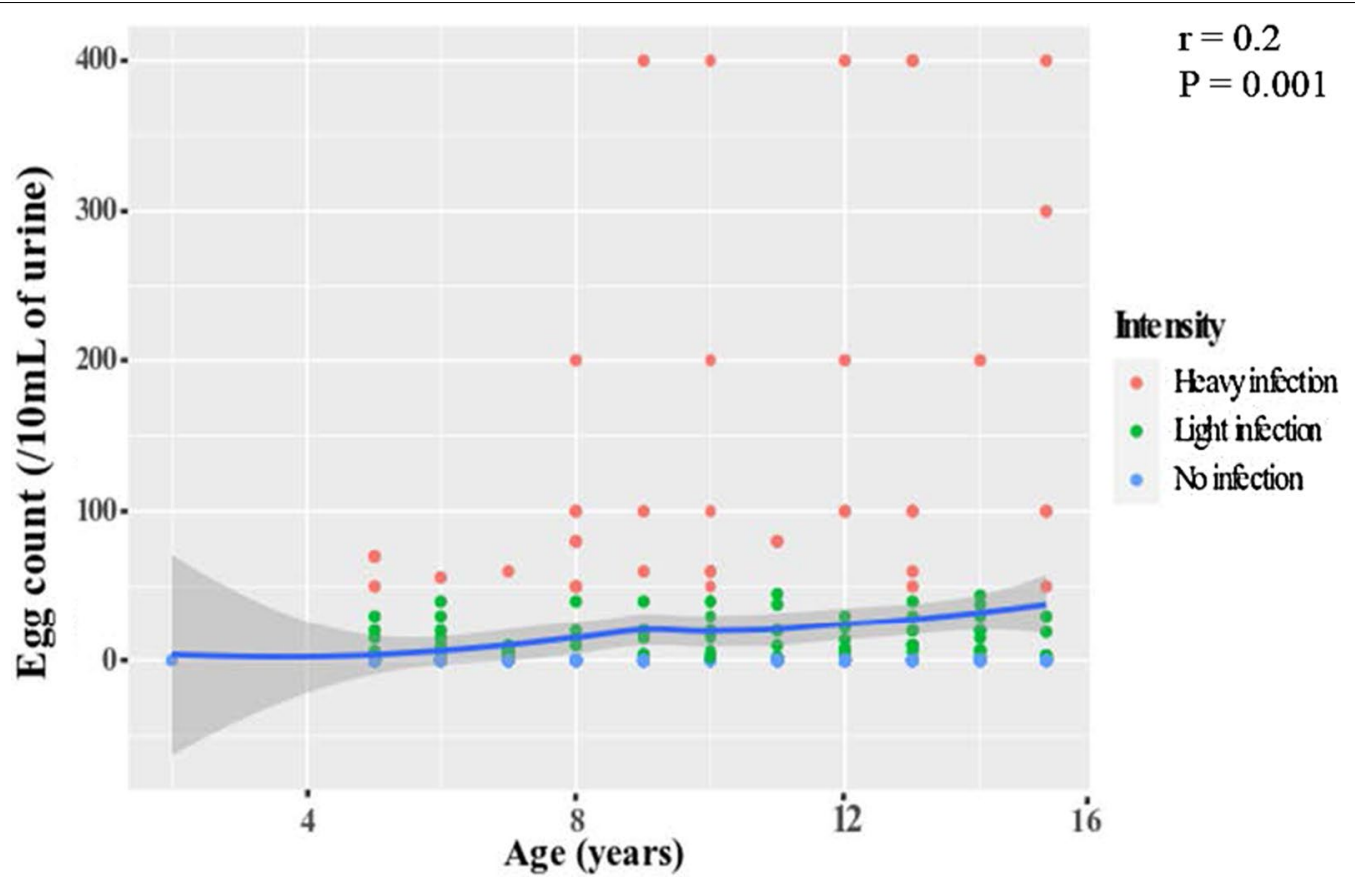

Fig. 2 Correlations between egg count and age of the participants

Table 3 Proportion of participants' awareness of urogenital schistosomiasis

\begin{tabular}{|c|c|c|c|}
\hline Question & Response & Frequency & Percent (\%) \\
\hline \multirow[t]{2}{*}{ Have you ever heard about schistosomiasis? } & Yes & 75 & 19.3 \\
\hline & No & 314 & 80.7 \\
\hline \multirow[t]{3}{*}{ Source of information about schistosomiasis } & School & 47 & 12.1 \\
\hline & Out of school & 27 & 6.9 \\
\hline & Do not know & 315 & 81.0 \\
\hline \multirow[t]{3}{*}{ How is the disease transmitted } & Water & 75 & 19.3 \\
\hline & Food & 0 & 0 \\
\hline & Do not know & 314 & 80.7 \\
\hline \multirow[t]{3}{*}{ What are the signs of schistosomiasis? } & Haematuria & 43 & 11.1 \\
\hline & Painful urination & 4 & 1.0 \\
\hline & Do not know & 342 & 87.9 \\
\hline \multirow[t]{2}{*}{ Do you know that the disease can be treated? } & Yes & 211 & 54.3 \\
\hline & No & 178 & 45.7 \\
\hline \multirow[t]{3}{*}{ What do you think should be done to prevent this disease? } & Treatment & 38 & 9.7 \\
\hline & Stop swimming & 29 & 7.5 \\
\hline & Do not know & 322 & 82.8 \\
\hline \multirow[t]{2}{*}{ Knowledge proportion } & Good & 90 & 23.1 \\
\hline & Poor & 299 & 76.8 \\
\hline
\end{tabular}

Table 4. In the bivariate analysis, SAC aged $12-15$ years (crude odds ratio $(\mathrm{COR})=2.37, P=0.001)$, being male (COR $=1.58, P=0.033)$, having good knowledge of UGS $(\mathrm{COR}=2.42, P=0.001)$, using water from stream for domestic purpose $(\mathrm{COR}=1.60, P=0.033)$ and stream water contact $(\mathrm{COR}=6.19, P=0.001)$ were identified as significant risk factors of UGS. On the other hand, in the multivariate analysis, while most 


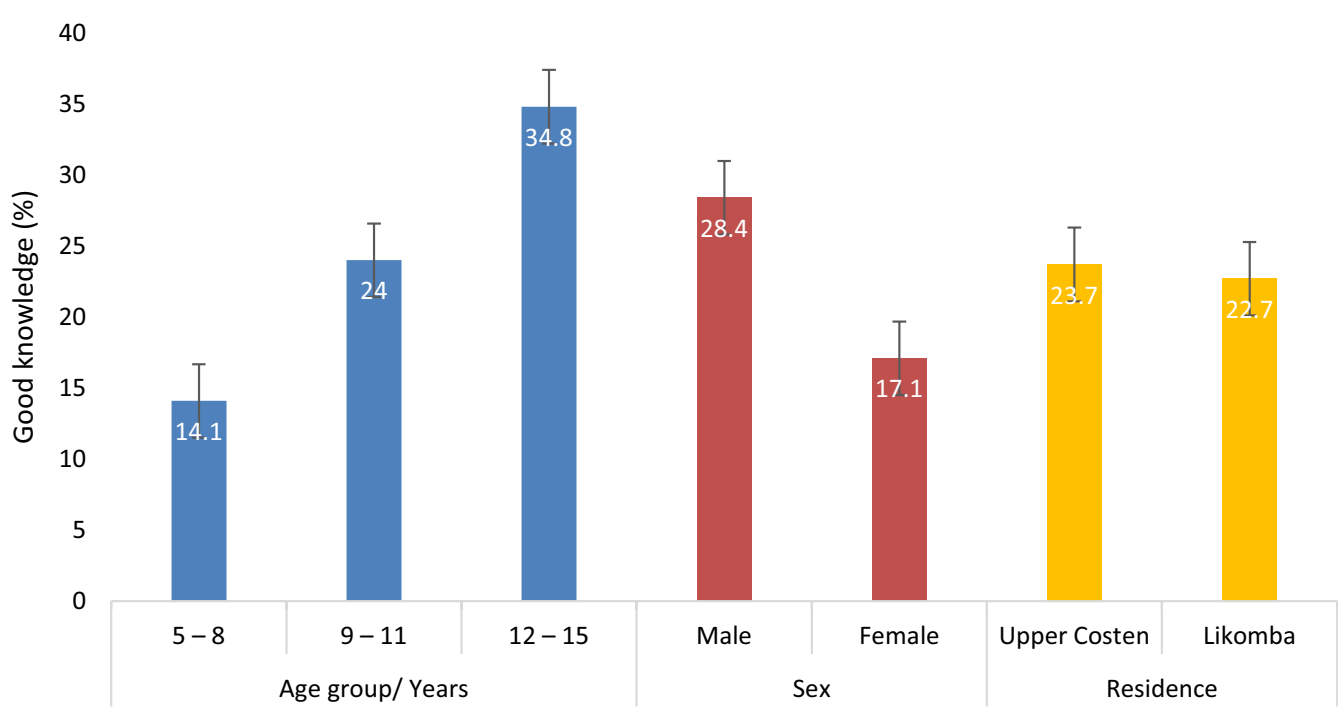

Fig. 3 Proportion of participants with good knowledge by age, sex and area of residence

Table 4 Bivariate and multivariate models showing factors associated with urogenital schistosomiasis prevalence

\begin{tabular}{|c|c|c|c|c|c|c|}
\hline \multirow[t]{2}{*}{ Variable } & \multirow[t]{2}{*}{$N$} & \multirow{2}{*}{$\begin{array}{l}\text { Urogenital schistosomiasis } \\
\text { prevalence }(n)\end{array}$} & \multicolumn{2}{|l|}{ Bivariate analysis } & \multicolumn{2}{|c|}{ Multivariate analysis } \\
\hline & & & COR $(95 \% \mathrm{Cl})$ & $P$-value & AOR $(95 \% \mathrm{Cl})$ & $P$-value \\
\hline \multicolumn{7}{|c|}{ Age group (years) } \\
\hline $5-8$ & 156 & $28.21(44)$ & Reference & & Reference & \\
\hline $9-11$ & 121 & $38.02(46)$ & $1.56(0.94-2.59)$ & 0.084 & $1.18(0.68-2.04)$ & 0.558 \\
\hline $12-15$ & 112 & $48.21(54)$ & $2.37(1.42-3.94)$ & 0.001 & $1.67(0.77-3.64)$ & 0.197 \\
\hline \multicolumn{7}{|l|}{ Gender } \\
\hline Female & 181 & $31.49(57)$ & Reference & & Reference & \\
\hline Male & 207 & $42.03(87)$ & $1.58(1.04-2.40)$ & 0.033 & $1.17(0.74-1.85)$ & 0.499 \\
\hline \multicolumn{7}{|c|}{ Educational level of parents } \\
\hline Secondary & 294 & $34.69(102)$ & Reference & & Reference & \\
\hline Primary & 95 & $44.21(42)$ & $1.49(0.93-2.39)$ & 0.096 & $1.23(0.59-2.58)$ & 0.587 \\
\hline \multicolumn{7}{|c|}{ Knowledge on schistosomiasis } \\
\hline Poor & 299 & $32.11(96)$ & Reference & & Reference & \\
\hline Good & 90 & $53.33(48)$ & $2.42(1.50-3.91)$ & 0.001 & $1.84(1.10-3.08)$ & 0.059 \\
\hline \multicolumn{7}{|c|}{ Source of water for domestic use } \\
\hline Tap & 196 & $32.14(63)$ & Reference & & Reference & \\
\hline Stream & 160 & $43.13(69)$ & $1.60(1.04-2.47)$ & 0.033 & $1.36(0.85-2.17)$ & 0.195 \\
\hline Well & 33 & $36.36(12)$ & $1.20(1.21-2.61)$ & 0.633 & $1.12(0.49-2.59)$ & 0.782 \\
\hline \multicolumn{7}{|c|}{ Stream water contact } \\
\hline No & 112 & $12.50(14)$ & Reference & & Reference & \\
\hline Yes & 277 & $46.93(130)$ & $6.19(3.37-11.36)$ & 0.001 & $4.94(2.63-9.29)$ & 0.001 \\
\hline
\end{tabular}

UGS, egg/haematuria positive; COR, crude odds ratio; AOR, adjusted odds ratio; $P$ values in bold are statistically significant

variables were potentially risk factors based on the adjusted odds ratio (AOR), only that of water contact was statistically significant $(\mathrm{AOR}=4.94, P=0.001)$ as shown in Table 4. 


\section{Discussion}

Due to lack of effective intervention programmes on the control and prevention of urogenital schistosomiasis, there is continuous resurgence and outbreaks. This study was carried out in the new focus in Tiko in the Mount Cameroon area with the main objective to generate baseline data on the prevalence of urogenital schistosomiasis in SAC, raise awareness through evaluation of knowledge of the disease as well as identify risk factors to enable strategic planning of control programmes to make use of the limited resources.

The prevalence of urogenital schistosomiasis in this study is higher than that reported in Maroua, in the Far North of Cameroon [25], and other communities in the Mount Cameroon area such as in Muyuka [26], Barombi Mbo [27], Ikata-Likoko area [28] and Kumba [29]. On the other hand, the prevalence is lower than that reported in other foci in regions like Munyenge [30], Kotto Barombi [31, 32] and Magba [33]. Although this study area was regularly targeted for control of geohelminths, schistosomiasis control was never given due attention since the focus is relatively new as a result of migration of infected population from the conflict-hit endemic foci in the Mount Cameroon area to the locality, probably accounting for the observed prevalence [16]. In addition, the other study areas are essentially rural areas with only community health care with limited pipe-borne water supply for domestic needs while Tiko is a semi-urban setting with improved social amenities. Even though urbanization reduces transmission points and the creation of modern water points limits the frequency of human water contacts as noted by Njiokou et al. [34], this has not had much of an impact in the communities studied due to their proximity to stream water sources that could be used for domestic purposes at no cost, rather than using pipe-borne water which is paid for.

Findings from the study demonstrated that urogenital schistosomiasis was significantly more common in males. This could be attributed to the higher tendencies of water contact through swimming, playing, and engagement in other domestic activities like fetching water and laundry in infested water bodies. This higher prevalence of schistosomiasis among males is in line with other studies performed elsewhere [35-37]. These findings are however contradictory to those of Sumbele et al. [26], Ntonifor et al. [38] and Ndamukong et al. [29], in other communities of the Mount Cameroon area in which the infection was more common in females.

Infection with $S$. haematobium was observed to be more common in children above 11 years of age than those below 10 years. The finding of higher prevalence in children above 11 years is in line with the study by Ntonifor et al. [30] and Kimbi et al. [39]. This however contradicts the findings of Njunda et al. [33] and Ebai et al. [28] who reported a higher prevalence of urogenital schistosomiasis in children 10 years and below, which could be attributed to the different behavioural pattern and cultural practices of the different study populations. As children grow older in semi-urban communities, the boys take up more difficult domestic tasks of fetching water and laundry and find pleasure in swimming in the stream for longer periods than the females.

The prevalence of urogenital schistosomiasis was not significantly different in school-aged children residing at Likomba and Upper Costen. The lack of such a difference might be due to the presence of several accessible water bodies at the centre of the town near residential areas where many children are always found bathing, swimming and doing laundry. This observation is in line with Kimbi et al. [39] and Campbell et al. [27], who also reported higher prevalence of urogenital schistosomiasis in children living near transmission sites.

The mean knowledge score and proportion of good knowledge of the disease is low with more males than females being knowledgeable of the disease in line with studies conducted by Kamga et al. [40] and Abdulkareem et al. [41]. This observation contradicts that of Aron et al. [42] in Tanzania who reported a higher proportion (92.4\%) of participants with knowledge on urogenital schistosomiasis attributed to its high occurrence. Alternatively, the poor knowledge of the disease in the Tiko endemic focus may be linked to the relatively short period of existence of the disease in the area hence, many children may not have experienced haematuria at any point in time in their life that would have probably raised awareness in the population unlike in highly endemic areas. Furthermore, consistent with other observations, older children were more knowledgeable of the disease than those younger [43]. These older children who are mostly on the course of secondary education can carry out more independent reading and quest for more information if need arises than their counterparts thus asserting that education improves knowledge. Interestingly, older children although more knowledgeable of the disease had the highest prevalence. This could probably be that the older children were not putting into practice their knowledge of schistosomiasis especially in the different preventive strategies of successful schistosomiasis prevention and control. Generally, older children take up more difficult domestic tasks of fetching water and laundry and find pleasure in swimming. Nevertheless, it is important to build and maintain broader understanding of schistosomiasis and its preventive strategies, especially environmental management, role of the vector and ways to control it. Therefore, well planned and locally sensitive ongoing public educational interventions are essential to 
educate and help communities to improve and sustain schistosomiasis knowledge and desired protective behaviour while addressing external factors such as environmental management.

Although male participants, children older than 11 years, having good knowledge of the disease, stream as a source of water for domestic use and stream water contact were 1.6-, 2.4-, 2.4-, 1.6- and 6.1-fold, respectively, more at risk of having urogenital schistosomiasis in the bivariate model, only contact with infested water body was identified as a risk factor in the multivariate model. This observation is not atypical as intense water contact activities have been attributed to the prevalence of infection elsewhere [41]. Infection occurs when cercaria, the larval form of the parasite is released by freshwater snails of the Genus Bulinus, penetrates the skin during contact with infested water. Hence, avoiding domestic and recreational activities such as swimming or fishing in infested water [44] may curb the spread of the disease.

While the design of the study gives a snapshot of information on the burden of urogenital schistosomiasis in school-aged children in this new endemic focus of Tiko, these findings are invaluable to health authorities in programming and re-structuring to include this area in the existing control programme in the country. The lack of detailed malacological information on the various streams existing in the community and detail assessment of intensity of water contact activities carried out is a major limitation to the study that demands further investigation to give a holistic picture on the epidemiology of urogenital schistosomiasis in the area.

\section{Conclusions}

These findings suggest that urogenital schistosomiasis is of public health concern among SAC in Tiko. The burden of infection is higher in males and children $12-15$ years with most of the participants having a poor knowledge about the disease. Hence, the population should be educated on vector-borne diseases and the avoidance of stream water contact which is the main risk factor identified in the study. Despite considerable efforts to scaleup activities to encompass all the regions in the country, coverage remains inadequate especially with the spread to other new foci, thus preventing the desired goals to be achieved. Hence, the preventive chemotherapy with praziquantel employed in other endemic focus in the region, should be supplemented with the provision of potable water in these communities to limit water contact activities in infested streams.

\section{Abbreviations}

UGS: Urogenital schistosomiasis; SAC: School-aged children; $x^{2}$ : Chi-square; COR: Crude odds ratio; AOR: Adjusted odds ratio; Cl: Confidence interval.

\section{Acknowledgements}

The authors are thankful to the parents/guardians as well as the school-aged children who participated in the study. We acknowledge the support of IIESRF (Institute of International Education- Scholar Rescue Fund) and MPH programme, College of Veterinary Medicine, Cornell University, Ithaca, New York, in providing the fellowship and right academic environment, respectively, for the co-writing of this manuscript.

\section{Author's contributions}

IUNS conceived, designed and supervised the study; participated in data analysis and interpretation; and a contributor to the write-up of the manuscript. DBT participated in the data collection, laboratory analysis and wrote the manuscript. RNT participated in the laboratory analysis, analysed and interpreted the data and revision of the manuscript. NAL participated in the study design, supervision and revision of the manuscript. All authors read and approved the final manuscript.

\section{Funding}

The study received no specific funding, however the study was supported by the special fund for research and modernization given to the authors by the Government of Cameroon.

\section{Availability of data and materials}

All datasets on which the conclusions of the research rely are presented in this paper. However, data are available from the corresponding author on reasonable request.

\section{Declarations}

\section{Ethics approval and consent to participate}

The study was approved by the Institutional Review Board hosted by the Faculty of Health Sciences, University of Buea (2018/0232/UB/SG/RB/FHS) following administrative clearance from the South West Regional Delegation of Public Health and the District medical officer for Tiko Health District, Cameroon. All participants gave their consent before being admitted into the study only after the assent of their parents or guardians. Confidentiality of records was assured.

\section{Consent for publication}

Not applicable.

\section{Competing interests}

The authors declare that they have no competing interests.

\section{Author details}

${ }^{1}$ Department of Zoology and Animal Physiology, University of Buea, Buea, Cameroon. ${ }^{2}$ Department of Medical Laboratory Science, University of Buea, Buea, Cameroon. ${ }^{3}$ Department of Microbiology and Immunology, College of Veterinary Medicine, Cornell University, Ithaca, NY, USA.

Received: 14 June 2021 Accepted: 1 September 2021 Published online: 16 September 2021

\section{References}

1. Huy NT, Elhadad H, Nam NH. Editorial overview of systematic reviews and meta-analyses on health in the tropics. Trop Med Health. 2019;47:47.

2. King $\mathrm{CH}$. Parasites and poverty: the case of schistosomiasis. Acta Trop. 2010;113(2):95-104

3. Steinmann P, Keiser J, Bos R, Tanner M, Utzinger J. Schistosomiasis and water resources development: systematic review, meta-analysis, and estimates of people at risk. Lancet Infect Dis. 2006;6:411-25.

4. WHO (2016). Global Health Estimates: Deaths by Cause, Age, Sex, by Country and by Region, 2000-2015. Geneva, World Health Organization. 2015

5. Adenowo AF, Oyinloyea BE, Ogunyinka BI, Kappo AP. Impact of human schistosomiasis in sub-Saharans Africa. Braz J Infect Dis. 2015;19(2):196-205. 
6. Pennington LF, Hsieh $\mathrm{MH}$. Immune response to parasitic infections. Bentham Books. 2014;2:93-124.

7. Bocanegra C, Pintar Z, Mendioroz J, Serres X, Gallego S, Nindia A, et al. Ultrasound evolution of pediatric urinary schistosomiasis after treatment with praziquantel in a highly endemic area. Am J Trop Med Hyg 2018;99(4):1011-7.

8. Engels D, Chitsulo L, Montresor A, Savioli L. The Global epidemiological situation of schistosomiasis and new approaches to control and research. Acta Trop. 2002:82:139-46.

9. Oluwatoyin FB. Urinary schistosomiasis. Pediatr Nephrol. 2014;29(11):2113-2110.

10. Sumbele IU, Otia OV, Bopda OS, Ebai CB, Kimbi HK, Nkuo-Akenji T. Polyparasitism with Schistosoma haematobium, Plasmodium and soiltransmitted helminths in school-aged children in Muyuka-Cameroon following implementation of control measures: a cross sectional study. Infect Dis Poverty. 2021;10(1):1-6.

11. Mas-Coma S, Valero MA, Bargues MD. Climate change effects on trematodes diseases, with emphasis on zoonotic fascioliasis and schistosomiasis. Vet Parasitol. 2009;163(4):264.

12. Teh RN, Sumbele IU, Nkeudem GA, Meduke DN, Ojong ST, Kimbi HK. Concurrence of CareStart ${ }^{\mathrm{TM}}$ malaria HRP2 RDT with microscopy in population screening for Plasmodium falciparum infection in the Mount Cameroon area: predictors for RDT positivity. Trop Med Health. 2019;47(1):1-1.

13. Tchuente LT, N'Goran EK. Schistosomiasis and soil-transmitted helminthiasis control in Cameroon and cote d'Ivoire: implementing control on a limited budget. Parasitol. 2009;136(13):1739-45.

14. Tchuem Tchuente LA, Momo SC, Stothard JR, Rollinson D. Efficacy of praziquantel and reinfection pattern in single and mixed infection foci for intestinal and urogenital schistosomiasis in Cameroon. Acta Trop. 2013;128(2):275-83.

15. $\mathrm{WHO}$, Preventive chemotherapy in human helminthiasis: coordinated use of anthelminthic drugs in control interventions: a manual for health professionals and programme managers. Geneva; WHO Press; 2006.

16. Anguh E, Ako S, Numfor E, Bimabam ZJ, Ndassi DV. Presence of an unmapped focus for urogenital schistosomiasis in the Tiko Health District in Cameroon: implications for control. IJTDH. 2018;32(2):1-8.

17. Ndassi VD, Anchang-Kimbi JK, Sumbele IU, Ngufor LA, Nadege K, Kimbi HK. The epidemiological status of urogenital schistosomiasis among reproductive aged individuals in the Tiko Health Area-a semi-urban setting in the Mount Cameroon area. PLOS Negl Trop Dis. 2021;15(1):e0008978.

18. Ebai CB, Kimbi HK, Sumbele IU, Yunga JE, Lehman LG. Efficacy and safety of praziquantel against Schistosoma haematobium in the Ikata-Likoko area of southwest Cameroon. Trop Med Health. 2017;45(1):1-8.

19. Sumbele IU, Asoba GN, Teh RN, Metuge S, Anchang-Kimbi JK, NkuoAkenji T. Burden of moderate to severe anaemia and severe stunting in children< 3 years in conflict-hit Mount Cameroon: a community based descriptive cross-sectional study. BMC pediatr. 2020;20(1):1-3

20. Saidu Y, Vouking M, Njoh AA, Bachire HB, Tonga C, Mofor R, Bayiha C, Ewane L, Cornelius C, Mbida ND, Abizou MB. The effect of the ongoing civil strife on key immunisation outcomes in the North West and South West regions of Cameroon. Confl Health. 2021;15(1):1-8.

21. United Nations High Commission on Refugees. Cameroon situation, responding to the needs of IDPs and Cameroonian refugees in Nigeria, Supplementary Appeal, January-December 2019. http://reporting.unhcr. org/sites/default/files/UNHCR\%20Came.

22. Bryan FJ. The design and analysis of research studies. UK: University of Otago, Cambridge University Press; 1992.

23. Cheesbrough M. District Laboratory practice in Tropical Countries part1 New York: Cambridge University press. 2014.

24. Kassa L, Omer A, Tafesse W, Taye T, Kebebew F, Beker A. Schistosomiasis: diploma program for the Ethiopian health center team. Ethiopia public health training initiative. 2005; pp. 8-18

25. Tchuenté LA, Momo SC, Stothard JR, Rollinson D. Efficacy of praziquantel and reinfection patterns in single and mixed infection foci for intestinal and urogenital schistosomiasis in Cameroon. Acta Trop. 2003;128(2):257-83.

26. Sumbele IU, Otia OV, Francis L, Bopda OS, Ebai CB, Ning TR, Kimbi HK, Nkuo-Akenji T. Confounding influences of malnutrition and Plasmodium falciparum and Schistosoma haematobium infections on haematological parameters in school children in Muyuka, Cameroon. BMC Infect Dis. 2021;21(1):1-3.

27. Campbell JS, Stothard JR, O'Halloran F, Sankey D, Durant T, Ombede DE, et al. Urogenital schistosomiasis and soil-transmitted helminthiasis (STH) in Cameroon: an epidemiological update at Barombi Mbo and Barombi Kotto crater lakes assessing prospects for intensified control interventions. Infect Dis Poverty. 2017;6(1):49.

28. Ebai CB, Kimbi HK, Sumbele IUN, Yunga JE, Lehman LG. Prevalence and risk factors of urinary schistosomiasis in the Ikata-Likoko area of Southwest Cameroon. IJTDH. 2016;7(2):2278-1005.

29. Ndamukong KJ, Ayuk MA, Dinga JS, Akenji TN, Ndiforchu VA, Titanji VP. Infection pattern of Schistosoma haematobium in primary school children of the Kumba Health District, South-West Cameroon. Afr J Health Sci. 2000;7(3-4):98-102.

30. Ntonifor HN, Green AE, Bopda MOS, Tabot JT. Epidemiology of urinary schistosomiasis and soil transmitted helminthiasis in a recently established focus behind Mount Cameroon. Int J Curr Microbiol App Sci. 2015;4:1056-66.

31. Nkengazong L, Njiokou F, Teukeng F, Enyong P, Wanji S. Reassessment of endemicity level of urinary schistosomiasis in the Kotto-Barombi focus (South West Cameroon) and impact of mass drug administration (MDA) on the parasitic indices. J Cell Anim biol. 2009;3(9):159-64.

32. Ndamukong KJ, Ayuk MA, Dinga JS, Akenji TN, Ndiforchu VA, Titanji VP. Prevalence and intensity of urinary schistosomiasis in primary school children of Kotto Barombi Health Area, Cameroon. East Afri Med J. 2001;78(6):287-9.

33. Njunda AL, Ndzi EN, Assob JCN, Kamga HF, Kwenti ET. Prevalence and factors associated with urogenital schistosomiasis among primary school children in barrage, Magba sub-division of Cameroon. BMC Public Health. 2017;17(1):1-9.

34. Njiokou F, Tsemo LCY, Kuete T, Ekobo AS. Dynamics of intestinal schistosomiasis in Cameroon: evolution of transmission in the mixed zone of Nkolmebanga. Lekie. Med Trop. 2004;64(4):351-4.

35. Wilkins HA, Goll PH, de C. Marshall, TF and Moore, PJ. Dynamics of Schistosoma haematobium infection in a Gambian community. III. Acquisition and loss of infection. Trans R Soc Trop Med Hyg. 1984: 78-80.

36. Rollinson D, Knopp S, Levitz S, Stothard JR, Tchuente LA, Garba A, et al. Time to set the agenda for schistosomiasis elimination. Acta Trop. 2013;128:423-40

37. Muhammad IA, Abdullahi K, Bala AY, Shinkafi SA. Prevalence of urinary schistosomiasis among primary school pupils in Wamakko local government, Sokoto state Nigeria. JOBAZ. 2019;80:22.

38. Ntonifor HN, Mbunkur GN, Ndaleh NW. Epidemiological survey of urinary schistosomiasis in some primary schools in a new focus behind mount Cameroon, south west region, Cameroon. EAMJ. 2012;89(3):82-8.

39. Kimbi HK, Wepnje GW, Kimbi J, Tonga C, Ayukenchengamba B, Njabi C, Kouodjip L, Nyabeyeu NJ, Lehman LG. Active case detection and prevalence of urinary schistosomiasis and malaria in pupils of Kotto Barombi, Southwest Cameroon Using the CyScope ${ }^{\circledR}$ Fluorescence Microscope. Int J of Trop Dis \& Health. 2015;8(1):1-12.

40. Kamga HLF, Njunda AL, Assob NJC, Bi-Suh AM, NdeFon P, Weledji P, et al. Schistosomiasis in Cameroon: an assessment of community knowledge pattern 2017. East Afr J Public Health. 2011;8(1):25-7.

41. Abdulkareem BO, Habeeb KO, Kazeem A, Adam AO, Samuel UU. Urogenital Schistosomiasis among schoolchildren and the associated risk factors in selected Rural Communities of Kwara State, Nigeria. J Trop Med. 2018;2018:6913918

42. Nzallah AW. Parasitological survey of Schistosoma haematobium infection among school children in Mkuranga District, Tanzania (Doctoral dissertation, Sokoine University of Agriculture). 2015

43. Martyn T, Sama EO, Ratard R. High risk behaviours and schistosomiasis infection in Kumba, South-West Province, Cameroon. Int J Environ Res Public Health. 2007;4(2):101-5.

44. WHO (2020). Schistosomiasis: Key facts. https://www.who.int/newsroom/fact-sheets/detail/schistosomiasis.

\section{Publisher's Note}

Springer Nature remains neutral with regard to jurisdictional claims in published maps and institutional affiliations. 